464 SCHOOL-AGE HEALTH SCREENINGS: SOMETHING OLD, SOMETHING NEW..

Ivana Pavic Simetin*. Croatian Institute of Public Health

10.1136/archdischild-2021-europaediatrics.464

The goal of this abstract is to give short insight into new national initiatives regarding school-age screenings in Croatia involving school health teams (school doctors and nurses).

Situation analysis based on the data from Croatian sample of the HBSC (Health Behavior in School-aged Children) study regarding mental health, and data from Dental Passport program regarding caries prevention.

According to the HBSC study, mental health indicators are the poorest among 15-year old pupils in comparison to 11and 13-year-old pupils, while girls report poorer mental health than boys: in 2018 at age 15, almost every day 10\% of girls and $3 \%$ of boys have headache, $15 \%$ of girls and $5,2 \%$ of boys feel depressed, $16,2 \%$ of girls and $6,2 \%$ of boys fill irritable, while $22,1 \%$ of girls and $10,7 \%$ of boys feel nervous. The pilot project on mental health screening among 15-years old pupils is conducted nationally as part of general examination of 1 st grade of high school's pupils in 2020, aiming to test the protocol for feasibility in different areas. The screening consists of self-administrated YP-CORE questioner for pupils followed by school doctor's clinical appraisal. Program Dental Passport started in school year 2016/2017. The program is based on dental form which 6grade-pupils (age 12) and children entering primary school (age 6) get from school doctors as referral to dentists for preventive examination. The number of 12-year-old pupils' visits to dental doctors considerably increased from 2015 to 2018 (September-December): 27586 visits in 2015 (before Dental Passport Program), 27586 visits in 2016, 67425 in 2017, and 80317 in 2018; Diagnostic and therapeutic procedures in dental health care increased from 30347 in 2015 to 63337 in 2018 (source: CEZIH).

Early detection is precondition for effective treatment and prevention of adverse health outcomes.

\section{GLOBAL CHILD RIGHTS DIALOGUE (GCRD): WHAT CHILDREN ACROSS THE GLOBE THINK ABOUT THEIR RIGHT TO HEALTH}

Ziba Vaghri* , Leyla Namazova. University of Victoria, Canada

\subsection{6/archdischild-2021-europaediatrics.465}

GlobalChild is an international project that is operationalizing the United Nations Convention on the Rights of the Child (CRC) using a comprehensive indicator framework to develop a global child rights monitoring platform.

The CRC is grounded on four guiding principles: non-discrimination; best interests of the child; the right to life, survival and development; and respect for the views of the child (child participation). Acting upon the principle of child participation as a guiding principle of the CRC, we launched the Global Child Rights Dialogue (GCRD) to seek children's opinions about their rights, with the objective to incorporate this feedback into the GlobalChild indicators.

We recruited facilitators across the globe to host workshops with children in their local areas. Using specially developed child-friendly versions of all substantive rights of the CRC, children were asked for their opinions about certain rights and how to know whether they were being implemented or not. Children at one of the sites in Russia specifically discussed articles

23 and 24: the rights to health and health services, and the rights of children with disabilities, respectively. Workshops followed Lundy's Model of Participation, which includes the four elements of space, voice, audience and feedback. First, children were informed about the right to be discussed to assist them to form and voice their opinions within the safe space of the workshop. Facilitators (the audience) listened to and recorded children's opinions. Upon analysis of all collected data, emerging themes were incorporated into the GlobalChild indicators. Finally, a child-friendly report was prepared to provide feedback to the children on how their input was used.

Data collected, from 1,836 children in 52 sites across the globe, confirmed that when children have a safe space, time, and a non-judgmental audience, they can share opinions and insights that are often underestimated by adults. These opportunities are conducive to improving development of the children, to teaching them active listening and to instilling values of tolerance and lifelong learning.

This presentation will share the collective input on articles 23 and 24 from children across the globe, as well as some of the specific outcomes from the workshops in Russia.

\section{CLINICAL AND EPIDEMIOLOGICAL FEATURES OF ACUTE RESPIRATORY VIRAL INFECTIONS IN CHILDREN}

Marina Fedoseenko*, M Fominykh, E Makushina, N Plenkovskaya, T Kaliuzhnaia, S Tolsrova, A Selvyan, T Privalova, F Shakhtakhtinskaya. Research Institute of Pediatrics of the Central Clinical Hospital under the Russian Academy of Medical Sciences, Moscow, Russia

\subsection{6/archdischild-2021-europaediatrics.466}

To assess clinical and epidemiological features of acute respiratory viral infections depending on the viral pathogen in children.

We retrospectively analysed 41 patients with symptoms of acute respiratory infection from birth to 18 years. Among the observed patients, there were prevailed children aged 1-5 years ( $\mathrm{n}=20$ children, 48.8\%), 13 infants $(31.7 \%)$ of the first year of life, and 8 children $(19.5 \%)$ over 5 years of age. Most patients were observed with a primary diagnosis of acute nasopharyngitis - 31.7\% ( $\mathrm{n}=13)$, acute bronchitis 29.3\% ( $\mathrm{n}=12)$, tracheobronchitis - 19.5\% ( $\mathrm{n}=8)$, obstructive bronchitis $-19.5 \%(n=8)$. Complicated forms of respiratory infection in the form of catarrhal otitis media, sinusitis were noticed in 3 children - 7.3\%, pneumonia - in 1 child (2.4\%). All patients underwent swab smear by polymerase chain reaction (PCR) to isolate viral pathogens of respiratory infections.

In half of the cases $(n=20,48.8 \%)$, the viral etiology was not established.

Rhinoviruses $(\mathrm{n}=9 ; 21.9 \%)$ and respiratory syncytial viruses (RSV) $(n=8 ; 19.5 \%)$ were the most common pathogens detected. Metapneumoviruses $(\mathrm{n}=4 ; 9.8 \%)$, adenoviruses $(n=2 ; 4.9 \%)$ and parainfluenza virus $(n=1 ; 2.4 \%)$ were significantly less common. Bocavirus and coronavirus were not detected. 